\title{
Correction to: Applying a dynamic ARDL approach to the Environmental Phillips Curve (EPC) hypothesis amid monetary, fiscal, and trade policy uncertainty in the USA
}

\author{
Roni Bhowmik $^{1,7} \cdot$ Qasim Raza Syed $^{2} \cdot$ Nicholas Apergis $^{3}$ (D) Andrew A. Alola ${ }^{4,5} \cdot$ Zeyu Gai $^{6}$
}

Published online: 26 October 2021

(c) Springer-Verlag GmbH Germany, part of Springer Nature 2021

Correction to: Environmental Science and Pollution Research (2021) 28:14115-14120 https://doi.org/10.1007/s11356-021-16716-y

The 2 nd affiliation of the 1 st Author is included in this paper.

Publisher's note Springer Nature remains neutral with regard to jurisdictional claims in published maps and institutional affiliations.

The online version of the original article can be found at https:// doi.org/10.1007/s11356-021-16716-y

Qasim Raza Syed qasim@ntc.gov.pk

Roni Bhowmik roni@amss.ac.cn

Nicholas Apergis napergis@unipi.gr

Andrew A. Alola andrew.alola@uwasa.fi

Zeyu Gai iqbalalam@nassg.org
Daffodil International University, Dhaka, Bangladesh

2 National Tariff Commission, Islamabad, Pakistan

3 University of Piraeus, Piraeus, Greece

4 School of Accounting and Finance, University of Vaasa, 65101 Vaasa, Finland

5 South Ural State University (National Research University), Chelyabinsk, Russian Federation, Russia

6 Nan Yang Academy of Sciences, Singapore, Singapore

7 School of Business, Guangdong University of Foreign Studies, Guangzhou, China 